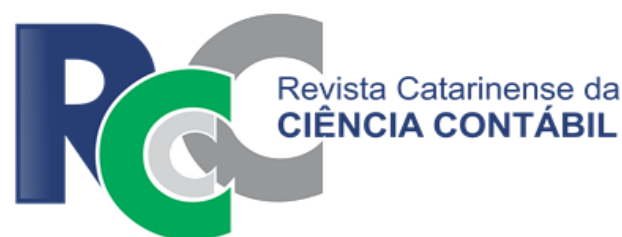
jan./abr. 2017

\title{
A TEORIA INSTITUCIONAL APLICADA À CONTABILIDADE GERENCIAL: ANÁLISE DA CONTRIBUIÇÃO TEÓRICA E METODOLÓGICA DE PUBLICAÇÕES INTERNACIONAIS OCORRIDAS NO PERÍODO DE 2006 A 2015*
}

\author{
INSTITUTIONAL THEORY APPLIED TO MANAGEMENT ACCOUNTING: ANALYSIS \\ OF THEORETICAL AND METHODOLOGICAL CONTRIBUTION OF INTERNATIONAL \\ PUBLICATIONS OCCURRED IN THE 2006-2015 PERIOD
}

\author{
JOSÉ LUIZ VAILATTI \\ Mestrando em Contabilidade na Universidade Federal de Santa \\ Catarina (UFSC). Professor do Instituto Fayal de Ensino Superior, \\ Empresário Contábil. Endereço: Rua Lico Amaral, 205, Ap. 65 / Dom \\ Bosco / 88307-010 / Itajaí/SC / Brasil. \\ E-mail:vailatti@conjel.com.br
}

\section{FABRICIA DA SILVA ROSA}

Doutora em Engenharia de Produção pela Universidade Federal de Santa Catarina (2011). Professora adjunta da Universidade Federal de Santa Catarina. Endereço: Universidade Federal de Santa Catarina, Departamento de Ciências Contábeis, Trindade | 88040-900 | Florianópolis/SC / Brasil.

E-mail: fabricia.rosa@ufsc.br

\begin{abstract}
ERNESTO FERNANDO RODRIGUES VICENTE
Doutor em Administração pela Universidade de São Paulo em 2004. Professor Associado do Departamento de Ciências Contábeis, do Centro Socioeconômico, da Universidade Federal de Santa Catarina (CCN/CSE/UFSC). Endereço: Universidade Federal de Santa Catarina, Departamento de Ciências Contábeis, Trindade / 88040-900 | Florianópolis/SC / Brasil.

E-mail: ernesto.vicente@ufsc.br
\end{abstract}

\section{RESUMO}

O objetivo da presente pesquisa é analisar as abordagens e metodologias utilizadas em pesquisas internacionais, que utilizaram a Teoria Institucional para avaliar aspectos de mudanças na utilização de práticas de contabilidade gerencial no período de 2006 a 2015. O trabalho caracteriza-se como descritivo com abordagem quantitativa. Utiliza-se um processo estruturado de revisão de literatura por meio de pesquisas nas bases EBSCO, EMERALD, SCOPUS, SCIELO, WEB OF SCIENCE. Foram identificados 21 artigos no período de 2006 a 2015, que estão alinhados com os eixos da pesquisa "Teoria Institucional" e "Contabilidade Gerencial". Foi realizada uma pesquisa bibliométrica para identificar a distribuição anual dos artigos por periódicos, natureza dos objetivos, número de autores por periódicos, abordagem teórica utilizada, abordagem do problema, técnicas de pesquisa, técnica de coleta de informações. Os resultados revelaram que a abordagem da Nova Sociologia Institucional dominou o cenário do estudo sobre mudanças em contabilidade gerencial. Todos os três processos de isomorfismo institucional parecem moldar o campo organizacional da pesquisa

*Artigo apresentado no XVI USP International Conference in Accounting no período de 27 a 29 de julho de 2016. 
em contabilidade. Foi identificado um pequeno número de pesquisas que utilizaram a abordagem da Velha Economia Institucional e nenhuma que tivesse utilizado a abordagem da Nova Economia Institucional. Mesmo poucas, destacou-se o crescimento das pesquisas que utilizaram a abordagem da Velha Economia Institucional e que avaliam as mudanças ocorridas em contabilidade gerencial do ponto de vista da organização.

Palavras-chave: Teoria Institucional. Contabilidade. Contabilidade Gerencial.

\begin{abstract}
The purpose of this research is to analyze the approaches and methodologies used in international research, which used the Institutional Theory to evaluate aspects of changes in the use of management accounting practices in the period 2006-2015. The study is characterized as descriptive with quantitative approach. It uses a structured process of literature review through research in EBSCO databases, EMERALD, SCOPUS, SCIELO WEB OF SCIENCE, where 21 articles were identified in the period 2006-2015 which are aligned to the axes of the survey "Institutional Theory "and" Management Accounting". A bibliometric research was carried out in order to identify the annual distribution of articles into periodicals, nature of the objectives, the number of authors for journals, theoretical approach, problem approach, research techniques, technical information collection. The results revealed that the approach of the New Institutional Sociology dominated the study setting on changes in management accounting. All the three institutional isomorphism processes seem to shape the organizational field of accounting research. A small number of research using the approach of Old Institutional Economics was identified and no research used the approach of the New Institutional Economics. Even though they were few, a growing number of research using the approach of Old Institutional Economics and which evaluate the changes in management accounting from the organization's point of view were found.
\end{abstract}

Keywords: Institutional Theory. Accounting. Management Accounting.

\title{
1INTRODUÇÃO
}

O Cenário de competitividade, as mudanças econômicas, o surgimento de novos produtos e a mudança no desejo do consumidor são alguns dos aspectos que fazem com que as empresas tenham que estar em constante evolução. Para isso, elas têm a sua disposição ferramentas, técnicas e instrumentos de gestão que auxiliam no processo decisório.

Nesse sentido, Reis (2011) afirma que o surgimento e a consequente disseminação de novas técnicas gerenciais para dar suporte ao processo de tomada de decisão acabam por provocar a quebra de antigos paradigmas, tendo em vista a forma permanente com que esses fatores acontecem.

No entanto, a implantação de novas técnicas contábeis não depende apenas da vontade da organização, mas também da capacidade das pessoas que a ela pertencem de implementarem as ferramentas à sua rotina de trabalho. As "rotinas" são hábitos pessoais e podem envolver grupos. Como tal, são os componentes de instituições. Em outras palavras, as rotinas são formalizadas ou os hábitos são institucionalizados. "Instituições" podem ser consideradas como impondo forma e coerência social sobre a atividade humana, em parte por meio da produção contínua e reprodução de hábitos de pensamento e ação. (Scapens, 1994; Burns \& Scapens, 2000).

Dentro do contexto do que são as instituições é que será possível compreende-lo o contexto das organizações, tendo em vista que "o conceito de instituições não é único e depende de qual vertente teórica é utilizada" (Frezatti, Rocha, Nascimento \& Junqueira, 2009, p. 227). Além disso, Frezatti et al. (2009) afirmam que a Teoria Institucional é utilizada para a compreensão da contabilidade dentro de um contexto específico, além de mostrar que essa ciência não pode ser analisada como um mero instrumento técnico isolado, deslocada do seu ambiente de atuação. 
O Estudo da Teoria Institucional tem despertado o interesse na área de ciências sociais e das diversas abordagens previstas na literatura de estudos organizações. No entanto, três possíveis enfoques dessa teoria vêm sendo utilizados na pesquisa contábil: Nova Economia Institucional, Velha Economia Institucional e Nova Sociologia Institucional (Burns \& Scapens, 2000; Guerreiro, Frezatti, Lopes \& Pereira, 2005; Reis, 2011).

De acordo com Guerreiro et al. (2005), o tema da estabilidade e da mudança nos sistemas de contabilidade gerencial tem sido pouco explorado em pesquisas no Brasil. Por outro lado constitui-se em tema relevante de pesquisa acadêmica no exterior, principalmente na Europa. Conforme o mesmo autor, o emprego da Teoria Institucional para explicar os fenômenos da estabilidade e da mudança nos sistemas contábeis gerenciais, tem sido uma das abordagens a ser utilizada.

Os principais estudos ligados à Teoria Institucional estão relacionados à Nova Sociologia Institucional. Conforme Frezatti et al. (2009), de acordo com levantamento feito no período de 1997 a 2007, 77\% dos trabalhos estavam relacionados à Nova Sociologia Institucional (NSI). Já os estudos em relação à Velha Economia Institucional (VEI) ou Nova Economia Institucional (NEI) representavam 9\% e $8 \%$ dos estudos do tema respectivamente.

Portanto, em virtude da importância do tema para avaliar as mudanças em contabilidade gerencial, é que se emerge o seguinte problema de pesquisa: Qual a abordagem teórica e metodológica sobre Teoria Institucional aplicada em Contabilidade Gerencial mais utilizada em pesquisas científicas em periódicos internacionais nos últimos 10 anos?

O presente estudo possui como objetivo analisar as abordagens e metodologias de pesquisas internacionais, que fizeram emprego da Teoria Institucional para avaliar as mudanças ocorridas na utilização da Contabilidade Gerencial no período de 2006 a 2015.

Este estudo se justifica devido à necessidade de identificar as diversas pesquisas que utilizaram a Teoria Institucional para relacioná-la com as práticas de Contabilidade Gerencial, tendo como objetivo explicar a utilização de ferramentas dentro das organizações, possibilitando assim identificar as contribuições da Teoria Institucional nas pesquisas.

\section{TEORIA INSTITUCIONAL}

Burns e Scapens (2000) sugerem que o ambiente em que a contabilidade gerencial é praticada certamente parece ter mudado, com os avanços da tecnologia da informação, mercados mais competitivos, diferentes estruturas organizacionais, e de novas práticas de gestão. Da mesma forma, Reis (2011) afirma que no ambiente de negócios da atualidade, em que uma das principais características é a alta competitividade entre as organizações, ocorre, de forma permanente, o surgimento e a consequente disseminação de novas técnicas gerenciais para dar suporte ao processo de tomada de decisão, o que acaba por provocar a quebra de antigos paradigmas.

Nesse contexto de quebra de paradigmas ocorreu a disseminação de técnicas de contabilidade gerencial, que já vinham sendo objeto de estudos acadêmicos e aplicações práticas apenas em poucas empresas. "Esse processo de mudança em Contabilidade Gerencial foi objeto de consideráveis estudos acadêmicos a partir dos anos 1990 com o interesse de pesquisa sendo direcionado a explorar assuntos relacionados a sistemas contábeis, técnicas contábeis e o papel do contador" (Reis, 2011, p. 332).

Pouca atenção tem sido dada à investigação para compreender os processos por meio dos quais esses novos sistemas e práticas de contabilidade gerencial foram incorporados ou não à rotina das empresas ao longo do tempo. No entanto, Scapens (1994) e Guerreiro et al. (2005) afirmam que o conhecimento teórico no âmbito da contabilidade gerencial é fortemente orientado pela teoria neoclássica da firma, mas essa teoria não se constitui em referencial teórico adequado para explicar o desenvolvimento de sistemas de contabilidade gerencial.

Para ajudar os pesquisadores a buscar uma forma de compreender melhor as mudanças ocorridas no contexto de contabilidade gerencial e que não podem ser respondidas pela teoria econômica neoclássica, surgiu a Teoria Institucional (Scapens, 1994; Guerreiro et al., 2005). Para um melhor entendimento do uso da Teoria Institucional e dos aspectos de 
mudanças, busca-se o estudo de Veblen (1898), que descartou a ideia de que as ações do indivíduo são explicáveis inteiramente em termos de circunstâncias socioeconômicas, sugerindo que os seres humanos são moldados pelas circunstâncias, assim como as circunstâncias são moldadas pelos indivíduos. Reis (2011) afirma que a análise de qualquer teoria deve estar pautada pelas características históricas e culturais. "A teoria clássica, oriunda do início do século XX e com ênfase nas tarefas, forneceu uma sólida compreensão de como estava ordenada a estrutura organizacional e como ela se desenvolvia dentro das análises estritamente mecanicistas" (Reis, 2011, p. 332).

De acordo com Hogdson (1998), em lugar de uma natureza humana passiva e substancialmente inerte e imutável, Veblen viu instintos e hábitos como as bases dinâmicas de intenção e ação. Além disso, Veblen (1898) afirma que a teoria de uma instituição pode ser expressa na forma habitual de como a vida é realizada, em que o indivíduo tende a manter o equilíbrio normal mesmo sobre novas condições formuladas e exigidas. Sendo assim, as mudanças que afetam os indivíduos decorrem de valores atribuídos e características compreendidas pelo ambiente.

Aspectos culturais também são levados em consideração dentro de uma instituição, pois podem refletir diretamente nos processos de mudanças. Veblen (1898) afirma, ainda, que uma economia evolutiva deve ser a teoria de um processo de crescimento cultural, conforme determinado pelo interesse econômico, uma teoria de uma sequência cumulativa de instituições econômicas expressas em termos do próprio processo. .

Assim sendo, a Contabilidade Gerencial, sob esse aspecto, que passará a ser denominado de Institucional, passa a ser compreendida, também, como um processo social, cujas pesquisas devem analisar como os valores sociais são ligados às ações econômicas, uma vez que muitas das ações adotadas em Contabilidade são implícitas e dificilmente detectadas pelas metodologias tradicionais (Reis, 2011).

Portanto, a Teoria Institucional compreende um conjunto de construtos teóricos advindos principalmente da economia, da sociologia e da ciência política. Suas três correntes fundamentais são a Velha Economia Institucional (VEI), a Nova Economia Institucional (NEI) e a Nova Sociologia Institucional (NSI). (Burns \& Scapens, 2000; Guerreiro et al., 2005; Frezatti et al., 2009; Reis, 2011).

Ao analisar os aspectos sobre estudos anteriores, que fizeram um levantamento dos periódicos internacionais, trataram do tema Teoria Institucional, destacam-se os trabalhos de Pereira (2012) e Cunha, Santos e Beuren (2015). O Trabalho de Pereira (2012) levantou 37 artigos no período de 2006 a 2012, pesquisados por meio das bases Sciense Direct, Emerald, Wiley Online Library, Mandeley, Oxford Jounals, JSTOR. Do Total de artigos pesquisados, constatou-se $56,76 \%$ de estudos que fizeram uso da abordagem da Velha Economia Institucional, 21,62\% que utilizaram a Nova Sociologia Institucional e 21,62\% que utilizaram ambas as abordagens.

Já os estudos de Cunha, Santos e Beuren (2015), pesquisaram apenas a base Science Direct até o ano de 2010. Identificaram 21 artigos que tratavam em seu tema de Teoria Institucional. No estudo apresentado, os autores identificaram que $52,3 \%$ utilizavam a abordagem da Nova Sociologia Institucional, enquanto 33,3\% utilizavam a VEI, 4,8\% a Nova Economia Institucional (NEI) e 9,6\% utilizavam tanto a VEI quanto a NSI. A seguir serão abordados os principais conceitos sobre Teoria Institucional, nas três vertentes utilizadas, para estudar os aspectos relativos à mudança em contabilidade gerencial.

\subsection{Velha Economia Institucional}

A Velha Economia Institucional (VEI) tem por objeto as chamadas "micro instituições". Realiza estudos sobre as relações entre os indivíduos no interior das organizações. Tem por objetivo analisar os comportamentos que produzem uma nova realidade social, que após um processo de mudança, possa ser considerada como institucionalizada (Reis, 2011).

Considerando a Teoria Institucional, segundo a ótica da (VEI), a Instituição é o principal objeto de análise e não mais o comportamento racional e maximizador dos indivíduos tomadores de decisões, conforme aceito pela teoria neoclássica. Assim, a conceituação de instituição é relevante, embora não exista uma definição simples e amplamente aceita (Reis, 
2011). No entanto, uma definição de Instituição dada por Veblen (1919) é: um determinado modo de pensar comum para um conjunto de pessoas.

$\mathrm{Na}$ avaliação de Burns e Scapens (2000), as próprias instituições evoluem por meio de um processo de rotinização da atividade humana. Assim, há uma dualidade entre a ação (atividade humana) e as instituições que estruturam essa atividade. Os mesmos autores ainda afirmam que rotinas organizacionais desempenham um papel importante na relação entre as ações e instituições.

A VEI vê o comportamento individual como uma importante parcela das instituições. Direciona de forma contundente a vida social e organizacional (Reis, 2011). As ações dos indivíduos da organização, modelada pelas regras e rotinas, no correr do tempo, fazem com que surjam instituições sedimentadas. Indivíduos atuando sob (e compartilhando) regras e rotinas contábeis tornam as instituições cristalizadas e referenciadas como socialmente adequadas (Burns \& Scapens, 2000; Guerreiro et al., 2005; Frezatti et al., 2009).

O processo de gestão da mudança em geral e a mudança da contabilidade gerencial especificamente demandam uma técnica de compreensão ampla do contexto no qual a organização está inserida, com ênfase em rotinas e instituições estabelecidas (Reis, 2011). No contexto da contabilidade gerencial, as regras compreendem os sistemas de contabilidade gerencial formais, de acordo com o que está definido nos manuais de procedimentos. Portanto, considerando que rotinas são as práticas contábeis realmente em uso, haverá uma relação entre as regras e rotinas, mas é importante não confundir as duas (Burns \& Scapens, 2000).

No contexto da Velha Economia Institucional, Burns e Scapens (2000) apresentaram um modelo do processo de institucionalização, representado pela Figura 1, composto dos seguintes passos: 1. Codificação; 2 Incorporação; 3 Reprodução; 4 Institucionalização.

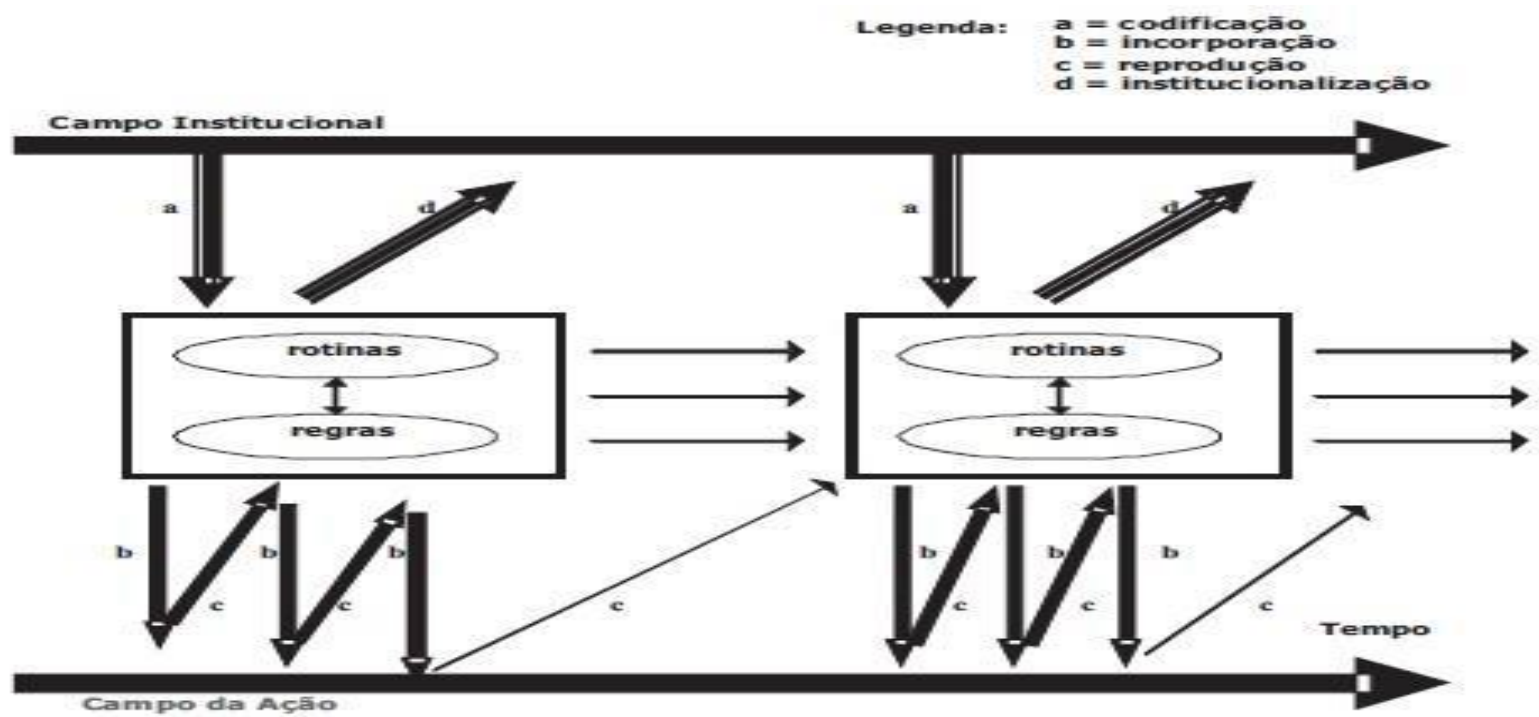

\section{Figura 1}

Modelo de mudança organizacional

Fonte: Guerreiro, Pereira e Frezatti (2008, p. 49) traduzido de Burns, J., \& Scapens, R. W. (2000). Conceptualizing management accounting change: an institutional framework. Management Accounting Research, 11, 3-25.

De acordo com os autores, o processo de institucionalização segue as seguintes fases:

1. De acordo com a Figura 1, Burns e Scapens (2000) apresentam o primeiro processo (seta a) que implica na codificação de princípios institucionais em regras e rotinas. Esse processo de codificação baseia-se em pressupostos de compreensão dos princípios institucionais por meio da criação de novos significados, valores e poderes existentes;

2. O segundo processo (seta $b$ ) envolve os atores articulados às rotinas (e regras) 
que modificam os princípios institucionais; Burns e Scapens (2000); Guerreiro et al. (2005) afirmam que o processo de incorporação pode envolver escolha consciente, mas normalmente é resultado de um monitoramento reflexivo e da aplicação do conhecimento tácito a respeito de como as coisas devem ser feitas;

3. O terceiro processo (seta c) ocorre como um comportamento repetido, que leva a uma reprodução das rotinas. Esta reprodução pode envolver mudança consciente ou inconsciente, como discutido anteriormente;

4. O quarto e último processo (seta d) é a institucionalização de normas e rotinas que foram reproduzidas por meio do comportamento dos atores individuais. Trata-se de uma dissociação dos padrões de comportamento de suas circunstâncias históricas particulares, de modo que as regras e rotinas assumem uma qualidade normativa e factual, o que obscurece sua relação com os interesses dos diferentes atores.

No processo de incorporação e reprodução das rotinas emergentes, as regras destinadas podem ser modificadas como formas aceitáveis de comportamentos. $O$ que é considerado aceitável será influenciado pelos significados e normas embutidas nas rotinas em andamento. Também os poderes dos atores individuais; tudo o que vai ser moldado pelas instituições existentes (Burns \& Scapens, 2000)

Assim, a gestão da mudança em geral, e da mudança de contabilidade gerencial, em particular, exige uma profunda compreensão do contexto atual da organização, especialmente suas rotinas e instituições (Burns \& Scapens, 2000). Portanto, a VEI pode contribuir para o entendimento sobre o processo de institucionalização de regras e rotinas no âmbito da contabilidade gerencial.

\subsection{Nova Economia Institucional}

Guerreiro et al. (2005) descrevem Coase (1937), North (1992) e Williamson (1992) como os principais teóricos no âmbito da Nova Economia Institucional. A Nova Economia Institucional (NEI) afirma que metodologicamente o indivíduo é racional, entretanto, com capacidade cognitiva restrita. Esses indivíduos atuam sob instituições econômicas que estruturam o seu comportamento (Frezatti et al., 2009, p. 231).

De maneira geral, os seguidores de Coase veem os custos de transação, que são menos perceptíveis que os custos de produção, como fator importante para o processo decisório nas empresas (Guerreiro et al., 2005; Reis, 2011). Os custos totais, dessa forma, seriam compostos dos custos de produção e dos custos de transação. Contudo, é comum o fato de as análises convencionais concentrarem-se somente nos custos de produção, mais fáceis de serem determinados (Reis, 2011).

Esse é o primeiro enfoque da Teoria Institucional, que tem por foco os custos de transação, e executa uma análise institucional a respeito de como os agentes se comportam, institucionalmente, em relação ao ambiente no qual está inserido, uma vez que este ambiente está permeado de imperfeições do mercado (Reis, 2011).

$\mathrm{Na}$ concepção da NEI, o custo de transação é o principal motivo para a existência de empresas. "Só existem empresas porque é mais barato realizar transações a partir de organizações do que com as pessoas agindo individualmente" (Frezatti et al, 2009, p. 232). Os instrumentos dessa abordagem teórica são os arranjos institucionais de contratos e organizações em ambiente competitivo, cuja administração de firmas é disciplinada pela pressão competitiva dos mercados (de bens, de mão de obra etc.) (Guerreiro et al., 2005).

Guerreiro et al. (2005) afirmam que a NEl foca o ambiente institucional como um conjunto de regras sociais, legais e políticas, que estabelecem as bases da produção, troca e distribuição, exercendo uma grande influência no comportamento das organizações econômicas. As organizações econômicas são um grupo de indivíduos envolvidos por um propósito comum de alcançar seus objetivos por meio das transações com o mercado.

Portanto, os custos de mensurar as múltiplas dimensões de produtos e serviços trocados ou de mensurar os desempenhos dos agentes e, também, os custos de promover acordos caracterizam os custos de transação (Guerrero et al., 2005). Outro pronto bastante importante é a observação da atividade econômica feita por Furubotn (2001). Ele sugere que 
os custos de transação positivos são onipresentes e inevitáveis, e que os tomadores de decisão são, por sua própria natureza, bastante limitados na capacidade de adquirir, armazenar, recuperar e processar informações.

Já os estudos de Willianson (1992), Vandenberg (2002), afirmam que a empresa é uma instituição no sentido de que as transações entre divisões representam a interação entre essas interfaces separáveis. Entre produzir ou comprar, a decisão é a chave e, na verdade, praticamente a única problemática do trabalho de Williamson (1992), e é analisada com referência a um número limitado de conceitos bem especificados (racionalidade limitada, oportunismo e de especificidade de ativos).

Já o trabalho de North (1992) é mais amplo. De acordo com Vandenberg (2002), inclui a tomada de decisão política e as atividades em sociedade civil, bem como as alterações que ocorrem durante longos períodos da história, abrangendo as relações intraorganizacionais e interorganizacionais privadas, bem como o desenvolvimento da relação jurídico-ambiente regulamentar que exige a compreensão do sistema político. Além disso, inclui os processos culturais, sociais e cognitivos que proporcionam uma norma estruturada e, portanto, também orientam a interação humana.

\subsection{Nova Sociologia Institucional}

Mudanças estruturais nas organizações parecem cada vez menos impulsionadas pela concorrência ou pela necessidade de eficiência. Ao invés disso a burocratização e outras formas de mudança organizacional ocorrem como o resultado de processos que tornam as organizações mais similares, sem, no entanto, torná-las mais eficientes (Dimaggio \& Powell, 1983).

Portanto, a Nova Sociologia Institucional (NSI) estuda como o ambiente institucional, composto de normas, crenças, tradições e necessidade de legitimidade, afeta o comportamento das organizações (Dimaggio \& Powell, 1983; Frezatti, et al., 2009). O principal conceito da NSI relevante à contabilidade gerencial é a noção de isomorfismo. Esse fenômeno corresponde à tendência que as organizações possuem em se assemelharem, em decorrência de pressões relacionadas ao ambiente externo, criando assim uma similaridade organizacional (Frezatti, et al., 2009). Ao nível da população, o Isomorfismo sugere que características organizacionais são modificadas no sentido de aumentar a compatibilidade com as características ambientais; o número de organizações em uma população é função da capacidade de suporte do meio ambiente; e a diversidade de formas organizacionais é isomorfo à diversidade ambiental (Dimaggio \& Powell, 1983)

Portanto, essa abordagem tem como unidade de análise as organizações. Estuda as mudanças em relação às práticas formais institucionalizadas, que buscam uma legitimidade externa, contribuindo com o atendimento das relações entre as estruturas organizacionais e 0 ambiente no qual estão inseridas (Reis, 2011).

Tendo em conta as pressões representadas no atual ambiente competitivo, já descritas anteriormente, pode-se considerar que as condições para que ocorra o isomorfismo institucional são propícias. Há um grau de dependência entre as empresas, que, aliada ao fenômeno da rapidez das mudanças, leva às incertezas e ao alto grau de conectividade dos sistemas de informação global e da sua complexidade resultante. Impelem as organizações a se tornarem cada vez mais parecidas (Reis, 2011).

DiMaggio e Powell (1983) identificaram três mecanismos de isomorfismos, dos quais as mudanças institucionais ocorrem, conforme apresentado na Tabela 1:

\section{Tabela 1}

Formas de isomorfismo institucional

\begin{tabular}{l|l}
\hline Isomorfismo & Definição \\
\hline Coercitivo & $\begin{array}{l}\text { Resultados de coercivas pressões formais e informais exercidas sobre organizações por outras } \\
\text { organizações de que eles são dependentes e por expectativas culturais da sociedade em que }\end{array}$ \\
& $\begin{array}{l}\text { as organizações funcionam. Tais pressões podem ser sentidas como força, persuasão, ou } \\
\text { como convites para participar em conluio. Em algumas circunstâncias, a mudança } \\
\text { organizacional é uma resposta direta ao mandato do governo. }\end{array}$ \\
\hline
\end{tabular}


Tabela 1 (continuação)

\begin{tabular}{l|l}
\hline Mimético & $\begin{array}{l}\text { Deriva da incerteza e de uma força poderosa que incentiva a imitação, pois quando as } \\
\text { tecnologias organizacionais são mal compreendidas, os objetivos são ambíguos, ou quando o } \\
\text { ambiente gera incertezas simbólicas, as organizações se modelam sobre outras organizações. }\end{array}$ \\
\hline Normativo & $\begin{array}{l}\text { Resulta principalmente da profissionalização. Dois aspectos são importantes fontes de } \\
\text { isomorfismo: um deles é o uso da educação formal e de legitimação em uma base cognitiva } \\
\text { produzida por especialistas universitários; o segundo é o crescimento e a elaboração de redes } \\
\text { profissionais que se estendem por organizações e por meio da qual os novos modelos se } \\
\text { difundem rapidamente. Além disso, em muitos casos, o poder profissional é atribuído pelo } \\
\text { Estado como no caso das atividades de profissionais liberais. }\end{array}$ \\
\hline
\end{tabular}

Nota. Fonte: adaptado de Dimaggio, P. J., \& Powell, W. W. (1983). The Iron Cage Revisited: Institutional Isomorphism and Collective Rationality in Organizational Fields. American Sociological Review, 48, 147-160.

A Tabela 1 revela de forma concisa o conceito de cada Isomorfismo identificado pelos autores. De acordo com DiMaggio e Powell (1983), no Isomorfismo Coercitivo pode ser dado como exemplo o fato de fabricantes adotarem novas normas contra a poluição por determinação do governo, entidades sem fins lucrativos que devem possuir contabilidade formal para cumprimento das normas. Portanto, vê-se no Isomorfismo Coercitivo, por exemplo, a mão do estado na organização social, tendo em vista a regulação de normas para o melhor convívio comum.

Com relação ao Isomorfismo Mimético, DiMaggio e Powell (1983) apresentaram como exemplo corporações americanas que estão implementando modelos japoneses para lidar com a produtividade pessoal e também para resolver grandes problemas em suas próprias empresas. A rápida proliferação do processo de gestão da qualidade e questões de qualidade de trabalho e vida pessoal em empresas americanas é, pelo menos em parte, uma tentativa de modelar sucessos japoneses e europeus.

DiMaggio e Powell (1983) consideram como mecanismo importante para incentivar isomorfismo normativo a filtragem de pessoal. Dentro de muitos campos organizacionais a filtragem ocorre por meio da contratação de indivíduos de empresas de um mesmo setor, por meio do recrutamento de pessoal de uma estreita gama de instituições de formação, por meio de práticas de promoção comuns, para a contratação de altos executivos de departamentos financeiros ou jurídicos e de requisitos de nível de habilidade para trabalhos específicos.

\section{METODOLOGIA}

Trata-se de uma pesquisa descritiva por descrever características de determinada população ou fenômeno ou estabelecimento de relações entre as variáveis. (Richardson, 1999; Beuren, 2014). Além disso, a presente pesquisa possui abordagem quantitativa, por se caracterizar pelo emprego de instrumentos estatísticos, tanto na coleta quanto no tratamento dos dados (Beuren, 2014). Esse tipo de estudo deve ser realizado quando o pesquisador deseja obter melhor entendimento do comportamento de diversos fatores e elementos que influem sobre determinado fenômeno (Richardson, 1999).

Em relação aos procedimentos operacionais de levantamento dos dados da pesquisa, foi utilizado um processo estruturado em 5 bases de dados de bancos de artigos científicos internacionais: EBSCO, EMERALD, SCOPUS, SCIELO, WEB OF SCIENCE.

Foram utilizados dois eixos de pesquisas: Teoria Institucional e Contabilidade Gerencial. E o período de análise corresponde aos anos de 2006 até 2015. Para o eixo de pesquisa Teoria Institucional, utilizou-se as seguintes palavras-chave: Institutional Theory, Old Institutional Economics, New Institutional Economics, New Institutional Sociology. Para o Eixo de Pesquisa Contabilidade Gerencial utilizou-se as seguintes palavras-chave: Accounting, Management Accounting, Management accounting change. A busca pelos artigos deu-se por meio das referidas palavras-chave identificadas no título, no resumo e nas palavras-chave dos artigos disponíveis nas bases de dados selecionadas para esta pesquisa.

Após a realização da consulta nas 05 bases, obteve-se um resultado de 1.783 artigos que em seguida foram exportados para o software Endnote $\mathrm{X} 7$, e excluídos os artigos duplicados, restando 1.362 artigos. Partiu-se então para a próxima etapa, a de exclusão de artigos com títulos não alinhados ao tema. Foram excluídos 1.327 artigos não alinhados à 
pesquisa, conforme a percepção do pesquisador, restando 35 artigos potenciais com títulos alinhados.

Para a etapa final foi realizada a leitura dos artigos alinhados e disponíveis gratuitamente nas bases de dados utilizadas no presente estudo. Desta forma, restaram 21 artigos para análise.

Após a seleção dos artigos que compõem a amostra deste estudo, realizou-se a análise para a verificação quanto a: i) Teoria Institucional Abordada; ii) Natureza do Objetivo; iii) Abordagem do Problema; iv) Procedimentos Técnicos; v) Técnicas de Coletas de Dados.

\section{RESULTADOS}

Nesta seção, inicialmente apresenta-se a relação dos artigos selecionados com os seus respectivos periódicos e ano de publicação. Após, evidencia-se a vertente da Teoria Institucional abordada, a natureza do objetivo, a abordagem do problema, os procedimentos técnicos e as técnicas de coletas de dados utilizadas nos artigos analisados. O Tabela 2 apresenta os artigos selecionados nas bases de dados EBSCO, EMERALD, SCOPUS, SCIELO, WEB OF SCIENCE, identificados pelo ano, título do artigo e pela revista em que foram publicados. Percebe-se que no período analisado houve uma frequência de publicação praticamente em todos os anos, com exceção do ano de 2010 , quando não houve qualquer publicação. Além disso, verifica-se que diversas revistas publicaram temas relativos a estudos de contabilidade gerencial, que utilizaram alguma abordagem da Teoria Institucional.

\section{Tabela 2}

Artigos selecionados nas bases de dados

\begin{tabular}{|c|c|c|c|}
\hline Seq & Ano & Título do Artigo & Revista \\
\hline 1 & 2006 & $\begin{array}{l}\text { Changes in accounting and financial information } \\
\text { system in a Spanish electricity company: A new } \\
\text { institutional theory analysis }\end{array}$ & Management Accounting Research \\
\hline 2 & 2007 & $\begin{array}{l}\text { Corporatisation and accounting change. The role of } \\
\text { accounting and accountants in a Malaysian public } \\
\text { utility }\end{array}$ & Management Accounting Research \\
\hline 3 & 2007 & $\begin{array}{l}\text { Beyond competition: Institutional isomorphism in U.S. } \\
\text { accounting research }\end{array}$ & Accounting Horizons \\
\hline 4 & 2008 & $\begin{array}{l}\text { Structuration theory and mediating concepts: Pitfalls } \\
\text { and implications for management accounting } \\
\text { research }\end{array}$ & Critical Perspectives on Accounting \\
\hline 5 & 2008 & $\begin{array}{l}\text { Accrual accounting does not necessarily mean } \\
\text { accrual accounting: Factors that counteract } \\
\text { compliance with accounting standards in Swedish } \\
\text { municipal accounting }\end{array}$ & Scandinavian Journal of Management \\
\hline 6 & 2009 & $\begin{array}{l}\text { Explaining the choice of accounting standards in } \\
\text { municipal corporations: Positive accounting theory } \\
\text { and institutional theory as competitive or concurrent } \\
\text { theories }\end{array}$ & Critical Perspectives on Accounting \\
\hline 7 & 2011 & $\begin{array}{l}\text { Routines in management accounting research: } \\
\text { Further exploration }\end{array}$ & $\begin{array}{l}\text { Journal of Accounting and Organizational } \\
\text { Change }\end{array}$ \\
\hline 8 & 2011 & $\begin{array}{l}\text { The role of consultant-researchers in the design and } \\
\text { implementation process of a programme budget in a } \\
\text { local government organization }\end{array}$ & Management Accounting Research \\
\hline 9 & 2012 & $\begin{array}{l}\text { Management accounting change and sustainability: } \\
\text { An institutional approach } \\
\end{array}$ & $\begin{array}{l}\text { Journal of Accounting and Organizational } \\
\text { Change }\end{array}$ \\
\hline 10 & 2012 & $\begin{array}{l}\text { Factors influencing the preparedness of large } \\
\text { unlisted companies to implement adapted } \\
\text { International Financial Reporting Standards in } \\
\text { Portugal }\end{array}$ & $\begin{array}{l}\text { Journal of International Accounting, Auditing } \\
\text { and Taxation }\end{array}$ \\
\hline 11 & 2012 & $\begin{array}{l}\text { Contracting out municipal accounting: The role of } \\
\text { institutional entrepreneurship }\end{array}$ & $\begin{array}{l}\text { Accounting, Auditing and Accountability } \\
\text { Journal }\end{array}$ \\
\hline 12 & 2012 & $\begin{array}{l}\text { An analysis of the deinstitutionalization of inflation- } \\
\text { adjusted accounting practices in Brazilian companies }\end{array}$ & Revista Contabilidade \& Finanças - USP \\
\hline
\end{tabular}


Tabela 2 (continuação)

\begin{tabular}{l|l|l|l}
\hline Seq & Ano & Título do Artigo & Revista \\
\hline 13 & 2013 & $\begin{array}{l}\text { An institutional perspective on the development of } \\
\text { Canada's first public accounts }\end{array}$ & Accounting History \\
\hline 14 & 2013 & $\begin{array}{l}\text { Balanced scorecard adoption in portuguese } \\
\text { organizations: Contingent and institutional variables }\end{array}$ & Intangible Capital \\
\hline 15 & 2013 & $\begin{array}{l}\text { The accounting profession's influence on academe: } \\
\text { South African evidence }\end{array}$ & $\begin{array}{l}\text { Accounting, Auditing and Accountability } \\
\text { Journal }\end{array}$ \\
\hline 16 & 2013 & $\begin{array}{l}\text { Different scenarios for accounting reform in non- } \\
\text { Anglophone contexts: The case of Japanese local } \\
\text { governments since the 1990s }\end{array}$ & Accounting History \\
\hline 17 & 2013 & $\begin{array}{l}\text { Management accounting change in an Egyptian } \\
\text { organization: An institutional analysis }\end{array}$ & $\begin{array}{l}\text { Journal of Accounting and Organizational } \\
\text { Change }\end{array}$ \\
\hline 19 & 2014 & $\begin{array}{l}\text { The development of accounting regulation in iraq and } \\
\text { the IFRS adoption decision: An institutional } \\
\text { perspective }\end{array}$ & International Journal of Accounting \\
\hline 20 & 2014 & $\begin{array}{l}\text { The reluctance of a developed country to choose } \\
\text { International Public Sector Accounting Standards of } \\
\text { the IFAC. A critical case study }\end{array}$ & $\begin{array}{l}\text { Critical Perspectives on Accounting } \\
\text { orientation to internationalization }\end{array}$ \\
\hline & 2015 & $\begin{array}{l}\text { The impact of cultural factors on the implementation } \\
\text { of global accounting standards (IFRS) in a } \\
\text { developing country }\end{array}$ & Advances in Accounting \\
\hline
\end{tabular}

Nota. Fonte: dados da pesquisa.

A Tabela 2 apresenta a distribuição anual dos artigos do periódico. Como pode ser observado, os anos de 2012, 2013 e 2014 foram os que tiveram os maiores números de publicações, com 12 trabalhos ao todo. Esse resultado está de acordo com as pesquisas de Pereira (2012) e Cunha, Santos e Beuren (2015), que afirmaram ter havido um aumento nos estudos sobre mudanças em contabilidade gerencial utilizando alguma abordagem da Teoria Institucional a partir de 2010.

A Tabela 3 apresenta ainda que o periódico Critical Perspectives on Accounting destacou-se com o maior número de publicações, com 4 artigos, representando $19,05 \%$ do total. Na sequência com 3 publicações destacam-se as revistas: Management Accounting Research e Journal of Accounting and Organizational Change. Portanto, 3 revistas representaram $47,63 \%$ das publicações em Teoria Institucional aplicadas à pesquisa em contabilidade gerencial. Justifica-se o maior número de pesquisas nessas revistas por trabalharem temas de contabilidade gerencial, comportamento humano, estruturas organizacionais. A pesquisa difere um pouco de Pereira (2012), que apresentou a revista International Business Review com maior número de publicações, e da pesquisa de Cunha, Santos e Beuren (2015), que teve como resultado a revista Management Accounting Research com maior número de publicações.

\section{Tabela 3}

Distribuição Anual dos Artigos por Periódicos

\begin{tabular}{|c|c|c|c|c|c|c|c|c|c|c|c|c|}
\hline \multirow[t]{2}{*}{ PERIÓDICOS } & \multicolumn{10}{|c|}{ Número de Artigos } & \multirow[t]{2}{*}{ Total } & \multirow[t]{2}{*}{$\%$} \\
\hline & 2006 & 2007 & 2008 & 2009 & 2010 & 2011 & 2012 & 2013 & 2014 & 2015 & & \\
\hline $\begin{array}{l}\text { Critical Perspectives on } \\
\text { Accounting }\end{array}$ & & & 1 & 1 & & & & & 2 & & 4 & 19,05 \\
\hline $\begin{array}{l}\text { Management Accounting } \\
\text { Research }\end{array}$ & 1 & 1 & & & & 1 & & & & & 3 & 14,29 \\
\hline $\begin{array}{l}\text { Journal of Accounting and } \\
\text { Organizational Change }\end{array}$ & & & & & & 1 & 1 & 1 & & & 3 & 14,29 \\
\hline $\begin{array}{l}\text { Accounting, Auditing and } \\
\text { Accountability Journal }\end{array}$ & & & & & & & 1 & 1 & & & 2 & 9,52 \\
\hline Accounting History & & & & & & & & 2 & & & 2 & 9,52 \\
\hline
\end{tabular}


Tabela 3 (continuação)

\begin{tabular}{|c|c|c|c|c|c|c|c|c|c|c|c|c|}
\hline \multirow[t]{2}{*}{ PERIÓDICOS } & \multicolumn{10}{|c|}{ Número de Artigos } & \multirow[t]{2}{*}{ Total } & \multirow[t]{2}{*}{$\%$} \\
\hline & 2006 & 2007 & 2008 & 2009 & 2010 & 2011 & 2012 & 2013 & 2014 & 2015 & & \\
\hline $\begin{array}{l}\text { Scandinavian Journal of } \\
\text { Management }\end{array}$ & & & 1 & & & & & & & & 1 & 4,76 \\
\hline $\begin{array}{l}\text { Journal of International } \\
\text { Accounting, Auditing and } \\
\text { Taxation }\end{array}$ & & & & & & & 1 & & & & 1 & 4,76 \\
\hline $\begin{array}{l}\text { Revista Contabilidade \& } \\
\text { Finanças - USP }\end{array}$ & & & & & & & 1 & & & & 1 & 4,76 \\
\hline Intangible Capital & & & & & & & & 1 & & & 1 & 4,76 \\
\hline $\begin{array}{l}\text { International Journal of } \\
\text { Accounting }\end{array}$ & & & & & & & & & 1 & & 1 & 4,76 \\
\hline Advances in Accounting & & & & & & & & & & 1 & 1 & 4,76 \\
\hline Total & 1 & 2 & 2 & 1 & 0 & 2 & 4 & 5 & 3 & 1 & 21 & 100,00 \\
\hline
\end{tabular}

Nota. Fonte: dados da pesquisa.

$\mathrm{Na}$ Tabela 4 buscou-se analisar os artigos quanto à natureza dos objetivos. É possível identificar que $62 \%$ apresentaram como natureza dos objetivos um estudo Prático. Esse resultado se aproxima do apresentado por Pereira (2012), que mostrou um pouco mais de $50 \%$ de trabalhos práticos. Contudo, é importante destacar que o estudo da Teoria Institucional permite diversas possibilidades de ampliação da teoria e também aplicação no que diz respeito ao entendimento dos fenômenos da realidade.

\section{Tabela 4}

Natureza dos Objetivos

\begin{tabular}{l|c|c}
\hline Natureza do Objetivo & Trabalhos & Percentual \\
\hline Teórico & 8 & $38 \%$ \\
\hline Prático & 13 & $62 \%$ \\
\hline Total & 21 & $\mathbf{1 0 0 \%}$ \\
\hline
\end{tabular}

Nota. Fonte: dados da pesquisa.

Quanto ao número de autores por periódicos, é possível verificar na Tabela 5 que, dos 21 artigos levantados, 8 apresentam pelo menos 2 autores, 6 artigos apresentam 3 autores e 5 artigos apresentam 1 autor apenas. Os artigos mostram que 48 autores participaram das pesquisas, o que representa um número variado dos que estudaram ou estudam o tema de mudanças em contabilidade gerencial com base na Teoria Institucional. O resultado difere um pouco da pesquisa de Cunha, Santos e Beuren (2015), em que 52,4\% dos artigos tiveram apenas 1 autor. Além disso, a revista Critical Perspectives on Accounting apresentou publicação de 11 autores diferentes, seguida pela Management Accounting Research, que teve um total de 7 autores que publicaram estudos sobre Teoria Institucional.

\section{Tabela 5}

Número de autores por artigo

\begin{tabular}{|c|c|c|c|c|c|c|c|c|}
\hline \multirow{2}{*}{ PERIÓDICOS } & \multicolumn{5}{|c|}{ Número de Autores } & \multirow{2}{*}{$\begin{array}{l}\text { Total } \\
\text { Artigos }\end{array}$} & \multirow{2}{*}{$\%$} & \multirow{2}{*}{$\begin{array}{c}\text { Total } \\
\text { Autores }\end{array}$} \\
\hline & 1 & 2 & 3 & 4 & 5 & & & \\
\hline Critical Perspectives on Accounting & 1 & 1 & 1 & & 1 & 4 & 19,05 & 11 \\
\hline Management Accounting Research & & 2 & 1 & & & 3 & 14,29 & 7 \\
\hline Journal of Accounting and Organizational Change & 3 & & & & & 3 & 14,29 & 3 \\
\hline Accounting, Auditing and Accountability Journal & & 1 & & 1 & & 2 & 9,52 & 6 \\
\hline
\end{tabular}




\begin{tabular}{|c|c|c|c|c|c|c|c|c|}
\hline \multirow{2}{*}{ PERIÓDICOS } & \multicolumn{5}{|c|}{ Número de Autores } & \multirow{2}{*}{$\begin{array}{l}\text { Total } \\
\text { Artigos }\end{array}$} & \multirow{2}{*}{$\%$} & \multirow{2}{*}{$\begin{array}{c}\text { Total } \\
\text { Autores }\end{array}$} \\
\hline & 1 & 2 & 3 & 4 & 5 & & & \\
\hline Accounting History & & 2 & & & & 2 & 9,52 & 4 \\
\hline Accounting Horizons & & 1 & & & & 1 & 4,76 & 2 \\
\hline Scandinavian Journal of Management & & 1 & & & & 1 & 4,76 & 2 \\
\hline $\begin{array}{l}\text { Journal of International Accounting, Auditing and } \\
\text { Taxation }\end{array}$ & & & 1 & & & 1 & 4,76 & 3 \\
\hline Revista Contabilidade \& Finanças - USP & & & 1 & & & 1 & 4,76 & 3 \\
\hline Intangible Capital & & & 1 & & & 1 & 4,76 & 3 \\
\hline International Journal of Accounting & & & 1 & & & 1 & 4,76 & 3 \\
\hline Advances in Accounting & 1 & & & & & 1 & 4,76 & 1 \\
\hline Total & 5 & 8 & 6 & 1 & 1 & 21 & 100,00 & 48 \\
\hline
\end{tabular}

Nota. Fonte: dados da pesquisa.

Os artigos também foram analisados quanto à abordagem teórica utilizada pelos autores para determinar a Teoria Institucional, a fim de explicar mudanças em contabilidade gerencial. A Tabela 6 mostra que $81 \%$ dos artigos fundamentaram os estudos sobre mudanças em contabilidade gerencial por meio da vertente da Nova Sociologia Institucional (NSI). 19\% dos artigos estavam fundamentados na vertente da Velha Economia Institucional (VEI). Não foram encontrados artigos que explicassem a mudança em contabilidade gerencial por meio da Nova Economia Institucional (NEI). Esse resultado diverge um pouco da pesquisa de Cunha, Santos e Beuren (2015), em que foi encontrado que 52,3\% dos estudos sobre a temática de mudanças em contabilidade gerencial estão na vertente da NSI, 33,3\% na vertente na da VEI e apenas $4,8 \%$ utilizaram a vertente da NEI. No entanto, a pesquisa de Pereira (2012) diverge tanto do resultado dessa pesquisa quanto do resultado apresentado por Cunha, Santos e Beuren (2015), de que 56,76\% utilizaram a VEI e 21,62\% utilizaram a NSI.

\section{Tabela 6}

Abordagem Teórica Utilizada

\begin{tabular}{l|c|c}
\hline Abordagem Teórica Utilizada & Trabalhos & Percentual \\
\hline Nova Economia Institucional - NEI & 0 & $0 \%$ \\
\hline Velha Economia Institucional - VEI & 4 & $19 \%$ \\
\hline Nova Sociologia Institucional - NSI & 17 & $81 \%$ \\
\hline Total & $\mathbf{2 1}$ & $\mathbf{1 0 0 \%}$ \\
\hline
\end{tabular}

Nota. Fonte: dados da pesquisa.

Quanto à abordagem do problema, $76 \%$ dos artigos são qualitativos, $19 \%$ quantitativos e $5 \%$ utilizaram ambas as abordagens. Portanto, observa-se na Tabela 7 a predominância dos estudos qualitativos, tendo em vista que na pesquisa qualitativa, por ser indutiva, os autores buscaram trazer estudos que pudessem ajudar a criar uma teoria acerca das mudanças no campo de contabilidade gerencial. As pesquisas de Pereira (2012) e Cunha, Santos e Beuren (2015) não apresentaram resultado quanto a esse tema.

\section{Tabela 7}

Abordagem do Problema

\begin{tabular}{l|c|c}
\hline Abordagem do Problema & Trabalhos & Percentual \\
\hline Qualitativa & 16 & $76 \%$ \\
\hline Quantitativa & 4 & $19 \%$ \\
\hline
\end{tabular}


Tabela 7 (continuação)

\begin{tabular}{l|c|c}
\hline Abordagem do Problema & Trabalhos & Percentual \\
\hline Qualitativa/Quantitativa & 1 & $5 \%$ \\
\hline Total & $\mathbf{2 1}$ & $\mathbf{1 0 0 \%}$ \\
\hline
\end{tabular}

Nota. Fonte: dados da pesquisa.

Quanto à análise de técnica de pesquisa, a Tabela 8 mostra que $38 \%$ dos artigos utilizaram a Pesquisa Bibliográfica e $33 \%$ a técnica de Levantamento, bem como que houve ainda $14 \%$ de pesquisas relacionadas a estudos de caso. Além disso, as técnicas de pesquisa documental, estudo etnográfico e também a pesquisa-ação foram utilizadas pro $5 \%$ cada. A pesquisa de Pereira (2012) apresentou alguns resultados um pouco divergentes, pois $29,73 \%$ dos estudos utilizaram um ensaio teórico, $18,91 \%$ uma revisão da literatura e $16,22 \%$ uma pesquisa documental e entrevista, ou um levantamento ou estudo de caso.

Tabela 8

Técnicas de pesquisa

\begin{tabular}{l|c|c}
\hline Técnica & Trabalhos & Percentual \\
\hline Pesquisa Bibliográfica & 8 & $38 \%$ \\
\hline Pesquisa Documental & 1 & $5 \%$ \\
\hline Levantamento & 7 & $33 \%$ \\
\hline Estudo de Caso & 3 & $14 \%$ \\
\hline Estudo Etnográfico & 1 & $5 \%$ \\
\hline Pesquisa-Ação & 1 & $5 \%$ \\
\hline Total & $\mathbf{2 1}$ & $\mathbf{1 0 0 \%}$ \\
\hline
\end{tabular}

Nota. Fonte: dados da pesquisa.

$\mathrm{Na}$ Tabela 9 são apresentadas as técnicas de coleta de informações utilizadas pelos autores. A técnica pode ser: observação, observação-participante, pesquisa documental, entrevista ou questionário.

\section{Tabela 9}

Técnica de coleta de informações

\begin{tabular}{l|c|c}
\hline Coleta de Informações & Trabalhos & Percentual \\
\hline Observação & 1 & $\mathbf{3} \%$ \\
\hline Observação Participante & 1 & $\mathbf{3} \%$ \\
\hline Pesquisa Documental & 11 & $\mathbf{3 5 \%}$ \\
\hline Entrevista & 7 & $\mathbf{2 3} \%$ \\
\hline Questionário & 7 & $\mathbf{2 3} \%$ \\
\hline Sem identificação & 4 & $\mathbf{1 3 \%}$ \\
\hline Total & 31 & $\mathbf{1 0 0 \%}$ \\
\hline
\end{tabular}

Nota. Fonte: dados da pesquisa.

Portanto, é possível observar na Tabela 9 que 35\% das pesquisas utilizaram a técnica de coleta de informações, uma pesquisa documental. $23 \%$ também utilizaram a entrevista e questionários para levantamento de dados. No entanto, em $13 \%$ dos artigos não foi possível identificar a técnica de coleta de informações utilizada. As pesquisas de Pereira (2012) e Cunha, Santos e Beuren (2015) não apresentaram resultado quanto a esse quesito. 


\section{CONCLUSÕES}

O presente trabalho teve como objetivo analisar a abordagem metodológica e o enfoque teórico abordado nos artigos publicados em periódicos internacionais no período de 2006 a 2015. Para isso, foi realizada uma pesquisa exploratório-descritiva, com abordagem quantitativa.

Foram identificados nesse período 21 artigos em periódicos internacionais que utilizaram a Teoria Institucional para explicar mudanças ocorridas em contabilidade gerencial. Os anos de 2012, 2013 e 2014 concentraram a maior parte das publicações, mostrando que há um crescimento em pesquisas ligadas ao tema, conforme comprovado por Pereira (2012) e Cunha, Santos e Beuren (2015).

O estudo também mostrou que o tema é publicado por diversas revistas diferentes, com destaque para a Critical Perspectives Accounting, Management Accounting Research e Journal of Accounting and Organizational Change, por apresentarem temas ligados à linha de pesquisa das referidas revistas. A pesquisa de Pereira (2012) apresentou um maior número de publicações na revista Management Accounting Research, o que confirma a tendência dessa revista na publicação do tema.

A pesquisa igualmente analisou a natureza dos objetivos. Pode ser identificado que $62 \%$ dos artigos tiveram natureza prática, num total de 48 autores para os 21 artigos. A maior parte dos artigos possui de 1 a 3 autores, o que de certa forma confirma a pesquisa de Cunha, Santos e Beuren (2015), que apresentou para a maioria dos artigos 1 autor apenas.

Com relação à abordagem da Teoria Institucional utilizada, $81 \%$ desses artigos abordam a Nova Sociologia Institucional para explicar as mudanças em contabilidade gerencial. Diverge um pouco dos resultados apresentados por Cunha, Santos e Beuren (2015). Portanto, a presente pesquisa mostrou que a abordagem da Nova Sociologia Institucional dominou o cenário do estudo sobre mudanças em contabilidade. $O$ enfoque dado sobre 0 Isomorfismo Institucional Normativo, Coercitivo e Mimético teve o objetivo de buscar a legitimidade via expectativas sociais. Outros estudos, ao aplicarem a Teoria Institucional no campo da pesquisa em contabilidade gerencial, propuseram que as influências institucionais, ao invés de forças competitivas, representam a atual exclusão de tópicos de contabilidade não financeira. Todos os três processos de isomorfismo institucional parecem moldar o campo organizacional da pesquisa em contabilidade gerencial.

No entanto, a abordagem da Teoria Institucional na vertente da Velha Economia Institucional (VEI) vem ganhando campo para explicar as mudanças em contabilidade gerencial. Foi observado em 4 estudos que o processo de institucionalização proposto por Burns e Scapens (2000) pode explicar os fatores para a implantação de novos processos ou ferramentas nas organizações, por meio da introdução de regras de controles, com a participação direta dos atores responsáveis pela execução desses processos (Englund \& Gerdin, 2008; Quinn, 2011; Bogt \& Helden, 2011; Youssef, 2013).

Observa-se uma lacuna de pesquisa para estudos que contemplam a Contabilidade Gerencial e a Teoria Institucional. A vertente da Velha Economia Institucional e da Nova Economia Institucional é explorada ainda de modo incipiente nas pesquisas acerca do tema, Também há poucos estudos que analisam de forma conjunta os tipos de abordagens institucionais. A Teoria Institucional mostrou-se útil para explicar aspectos de mudanças em contabilidade gerencial, tendo em vista fazer com que ferramentas gerenciais possam ser institucionalizadas dentro de organizações.

Para pesquisas futuras, poderão ser realizados estudos em bases nacionais, em comparação com as pesquisas em bases internacionais, além da exploração de seus conteúdos, objetivando identificar em quais circustâncias a Teoria Insitucional é utilizada para explicar mudanças ocorridas em contabilidade gerencial.

\section{REFERÊNCIAS}

Beuren, I. M. (2014). Como elaborar trabalhos monográficos em contabilidade: teoria e prática (1a ed.). São Paulo: Atlas. 
Bogt, H. J. T., \& Helden, G. J. V. (2011). The role of consultant-researchers in the design and implementation process of a programme budget in a local government organization. Management Accounting Research, 22, 56-64.

Burns, J., \& Scapens, R. W. (2000). Conceptualizing management accounting change: an institutional framework. Management Accounting Research, 11, 3-25.

Cunha, P. R. D., Santos, V. D., \& Beuren, I. M. (2015). Artigos de periódicos internacionais que relacionam teoria institucional com contabilidade gerencial. Revista Perspectivas Contemporâneas, 10 (2), 01-23.

Dimaggio, P. J., \& Powell, W. W. (1983). The Iron Cage Revisited: Institutional Isomorphism and Collective Rationality in Organizational Fields. American Sociological Review, 48, 147-160.

Englund, H., \& Gerdin, J. (2008). Structuration theory and mediating concepts: Pitfalls and implications for management accounting research. Critical Perspectives on Accounting, $19,1122-1134$

Frezatti, F., Rocha, W., Nascimento A. R. \& Junqueira, E. (2009). Controle Gerencial: Uma Abordagem da Contabilidade Gerencial no Contexto Econômico, Comportamental e Sociológico (1 $1^{\text {a }}$. ed.). São Paulo: Atlas.

Furubotn, E. G. (2001). The new institutional economics and the theory of the firm. Journal of Economic Behavior \& Organization, 45, 133-153.

Guerreiro, R., Frezatti, F., Lopes, A. B., \& Pereira, C. A. (2005). O entendimento da contabilidade gerencial sob a ótica da teoria institucional. $O \& S, 12$ (35), 91-106.

Hodgson, G. M. (1998). On the evolution of Thorstein Veblen's evolutionary economics. Cambridge Journal of Economics, 36, 415-431.

Pereira, F. A. (2012). A evolução da teoria institucional nos estudos organizacionais: um campo de pesquisa a ser explorado. Organizações em contexto. 8 (16). 275-295.

Quinn, M. (2011). Routines in management accounting research: Further exploration. Journal of Accounting and Organizational Change, 7. 337-357.

Reis, L. G. (2011). Tendências de Estudos em Contabilidade Gerencial, sob a Ótica da Teoria Institucional. In C. Parisi \& E. Megliorini (Org.). Contabilidade Gerencial. (1 ${ }^{\text {a }}$ Ed. Cap. 15, pp. 331-346). São Paulo: Atlas.

Richardson, R. J. (2012). Pesquisa Social: métodos e técnicas (3a ed.). São Paulo: Atlas.

Scapens, W. R. (1994).Never mind the gap: towards na institutional perspective on management accounting practice. Management Accounting Research, 5, 301-321.

Vandenberg, P. (2002). North's Institutionalism and the prospect of combining theoretical approaches. Cambridge Journal of Economics, 26, 217-235.

Veblen, T. (1898). Why is Economics not an Evolutionary Science? Oxford University Press, 12, 376-397.

Veblen, T. (1919). The Place of Science in Modern Civilization and Other Essays. New York.

Youssef, M. A. (2013). Management accounting change in an Egyptian organization: An institutional analysis. Journal of Accounting and Organizational Change, 9, 50-73. 